Çukurova Üniversitesi Mühendislik Mimarlık Fakültesi Dergisi, 30(1), 249-256 ss., Haziran 2015

Çukurova University Journal of the Faculty of Engineering and Architecture, 30(1), pp. 249-256, June 2015

\title{
Tabakalı Zeminlere Oturan Dairesel Temellerin Deney ve Analitik Yöntemle İrdelenmesi
}

\author{
Gizem MISIR $^{* 1}$, Mustafa LAMAN ${ }^{1}$ \\ ${ }^{1}$ Çukurova Üniversitesi, Mühendislik Mimarlık Fakültesi, İnşaat Mühendisliği Bölümü, Adana
}

Geliş tarihi: 10.06 .2015

Kabul tarihi: 18.06 .2015

\section{Özet}

Bu çalışmada, yoğrulmuş kil zeminler üzerine inşa edilen granüler dolgu tabakasına oturan dairesel temellerin yük taşıma kapasiteleri, 6 ve $9 \mathrm{~cm}$ çaplı temeller için, laboratuvar model deneyleri ile incelenmiştir. Deneyler sonucunda yük-oturma eğrileri çizilerek, dairesel temellerin taşıma gücü ve oturma davranışları incelenmiştir. İki farklı temel çapı için karşılaştırma yapıldığında, ölçek etkisinin bulunmadığı görülmüştür. Deneysel veriler literatürde sunulan analitik bir bağıntı ile karşılaştırılarak, uyum içerisinde olduğu görülmüştür.

Anahtar Kelimeler: Dairesel temel, Tabakalı zemin, Model deney, Taşıma kapasitesi

\section{Investigation of the Circular Footings Resting on a Layered Soils by Experimental and Analytical Methods}

\begin{abstract}
In this study, bearing capacity of the circular footings rested on a granular fill layer that was constructed on a remolded clay soil were examined by using the laboratory model tests for the footings diameters of 6 and $9 \mathrm{~cm}$. At the end of the tests, the bearing capacity and the settlement behaviours of the footing were evaluated from load settlement curves. The scale effect was checked and it is concluded that there is not any scale effect by the comparison of the results of the two different footing diameters. Experimental results were compared with the results of analytical method and the consistency was obtained.
\end{abstract}

Keywords: Circular footing, Layered soil, Model test, Bearing capacity

\footnotetext{
*Yazışmaların yapılacağı yazar: Gizem MISIR, Mühendislik Mimarlık Fakültesi, İnşaat Mühendisliği Bölümü, Adana.gmisir@cu.edu.tr
} 


\section{GíRiş}

Yapım teknikleri ve yapım teknolojisindeki gelişmeler ile kentlerde yapılaşma hızla gelişmiş ve buna bağlı olarak yapıların inşa edilmesi için uygun arazilerin bulunmasında sikıntılar doğmuştur. Kent merkezlerinde yer alan, ancak taşıma gücü ve oturma açısından, problemli olan arazilerin, yapılaşmaya uygun hale gelmesi için bu alanlarda çok katlı ve özellikli yapıların temel sistemi derin temele dönüştürülmekte ya da zeminlerinin iyileştirilmesi yoluna başvurulmaktadır. Zeminlerin iyileştirilmesi için, granüler stabilize dolgu yöntemi uygulamada kullanılan alternatif iyileştirme yöntemlerinden biridir. Granüler dolgu ile iyileştirme yönteminde zemin, özellikleri ve davranışı önceden yapılan laboratuvar deneyleri ile belirlenmiş olduğundan, bir bakıma iyileştirme yapılan, sorunlu bölge kontrol altına alınmış olmaktadır. Yumuşak kil zeminlerde dolgu tabakası yerleşimi ile şerit temelin taşıma kapasitesinde meydana gelen iyileştirmeler konusunda literatürde [1] ve [2] ile başlayan, tabaklı zemin davranışını inceleyen çeşitli teorik yaklaşımlar bulunmaktadır.

$\mathrm{Bu}$ çalışmada, granüler dolgu ile iyileştiren yumuşak kil zeminlere oturan dairesel temellerin taşıma kapasitesi, bir seri model deney çalışması ile incelenmiştir. Model deneylerde; yüzeysel temel olarak 6 ve $9 \mathrm{~cm}$ çaplarında dairesel model temeller, zemini güçlendirmek amaciyla da temel çapına bağlı olarak farklı kalınlıklarda $(0,25 \mathrm{D}$, 0,50D, 1,00D, 1,50D) stabilize dolgu kullanılmıştır. Laboratuvar model deneyleri ile tabakalı zeminlere oturan temellerin taşıma kapasiteleri analitik bir çözüm yöntemi ile de karşılaştırılmıştır.

\section{DENEYSEL ÇALIŞMALAR}

Bu çalışma, yumuşak kil zemin üzerinde granüler stabilize dolgu tabakası yerleşimi ile yapılan küçük ölçekli laboratuvar yükleme deneylerini içermektedir. Deneyler, laboratuvar ortamında, doğal su içeriğinde hazırlanan numuneler üzerinde gerçekleştirilmiştir. Çalışma ile, kil tabakası üzerine farklı derinliklerde yerleştirilen granüler stabilize dolgu tabakasının, kil zeminin taşıma gücüne olan etkileri araştırılmıştır.

\subsection{Kil Zemin Özellikleri}

Model deney çalışmalarında kullanılan killi zemin, Adana İli, Seyhan İlçesi, Yenidam Köyü Mevkiinden, granüler dolgu için kullanılan stabilize malzeme ise, Adana İli Kabasakal Mevkiinden getirilmiştir. Söz konusu arazide açılan muayene çukuru ve sondaj kuyularından örselenmiş ve örselenmemiş zemin numuneleri alınarak laboratuvara getirilmiştir. Araziden alınan killi zeminler ve ocaktan getirilen stabilize malzeme üzerinde endeks ve mühendislik özelliklerinin belirlenmesine yönelik deneyler, Çukurova Üniversitesi, İnşaat Mühendisliği Bölümü Zemin Mekaniği Laboratuvarında gerçekleştirilmiştir.

Çalışma sahasındaki zemin özelliklerinin belirlenmesi için arazide 2,00-2,50 m derinlikte iki adet muayene çukuru ve 13-20 m arasında değişen derinliklerde 4 adet sondaj kuyusu açılmıştır. Açılan sondaj kuyularından SK1 ve SK2'den elde edilen zemin tabakaları bir arada değerlendirildiğinde Şekil 1'deki zemin profili elde edilmektedir. 5 m'lik zemin profilinde ilk $1 \mathrm{~m}$ bitkisel toprak olduğundan göz ardı edilmiştir. Kil zemine ait malzeme parametreleri Çizelge 1'de verilmiştir.

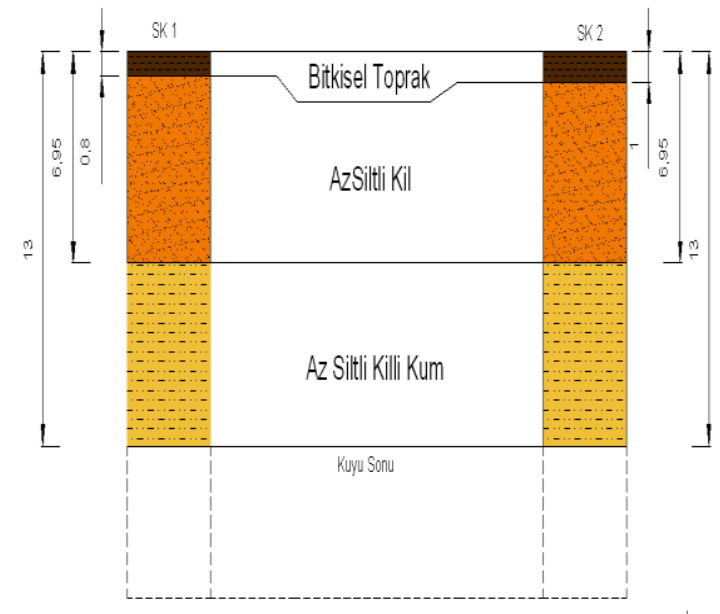

Şekil 1. SK1 ve SK2'ye ait blok diyagramı [3] 
Çizelge 1. Kil zemine malzeme parametreleri [4]

\begin{tabular}{|c|c|c|c|}
\hline Depth & $1.0-2.2 \mathrm{~m}$ & $2.2-3.5 \mathrm{~m}$ & $3.5-5.0 \mathrm{~m}$ \\
\hline $\begin{array}{c}\text { Kil } \\
\text { Zemin }\end{array}$ & $\mathrm{CH}$ & $\mathrm{CL}$ & $\mathrm{CL}$ \\
\hline $\begin{array}{c}\mathrm{w} \\
(\%)\end{array}$ & $20,0-21,0$ & $22,0-24,0$ & $22,0-24,0$ \\
\hline $\begin{array}{c}\gamma_{\mathrm{n}} \\
\left(\mathrm{kN} / \mathrm{m}^{3}\right)\end{array}$ & $19,5-20,5$ & $19,3-22,5$ & $20,8-21,5$ \\
\hline $\begin{array}{c}\gamma_{\mathrm{s}} \\
\left.\mathrm{kN} / \mathrm{m}^{3}\right)\end{array}$ & $25,7-26,0$ & $26,0-26,9$ & $25,7-26,6$ \\
\hline $\begin{array}{c}\mathrm{w}_{\mathrm{L}} \\
(\%)\end{array}$ & $51,0-69,0$ & $28,0-54,0$ & $37,0-44,0$ \\
\hline $\begin{array}{c}\mathrm{w}_{\mathrm{P}} \\
(\%)\end{array}$ & $21,0-30,0$ & $19,0-22,0$ & $20,0-25,0$ \\
\hline $\begin{array}{c}\mathrm{c}_{\mathrm{u}} \\
(\%)\end{array}$ & $60,0-80,0$ & $65,0-75,0$ & - \\
\hline
\end{tabular}

\subsection{Stabilize Malzeme Özellikleri}

Adana İli, Kabasakal Mevkiindeki ocaktan getirilen stabilize malzeme üzerinde, elek analizi, su muhtevası, birim hacim ağırlığ ve Standart Proctor deneyleri yapılmıştır. Standart Proctor deneyinden, zeminin maksimum kuru birim hacim ağırlığı $2,17 \mathrm{t} / \mathrm{m}^{3}$, optimum su içeriği ise, \% 7 olarak belirlenmiştir (Şekil 2).

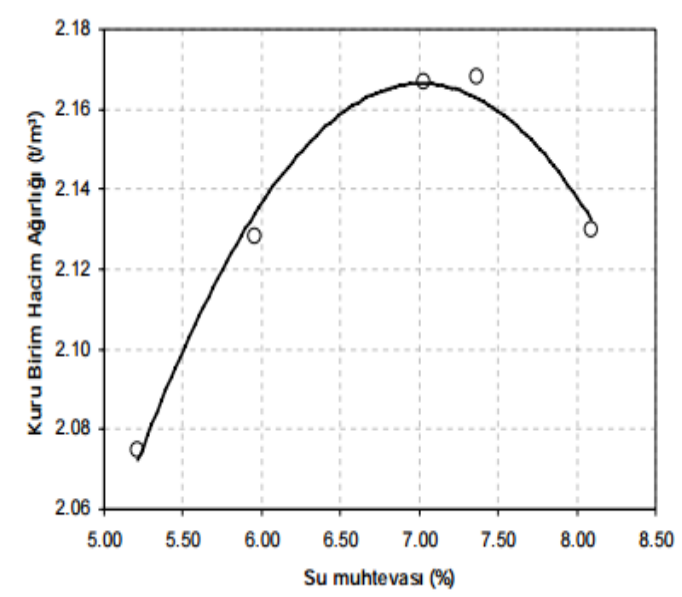

Şekil 2. Standart proktor deney sonucu [3]

Granüler stabilize malzeme üzerinde yapılan kesme kutusu deneyi ile zeminin içsel sürtünme açısının $43^{\circ}$ mertebelerinde olduğu bulunmuştur (Şekil 3).

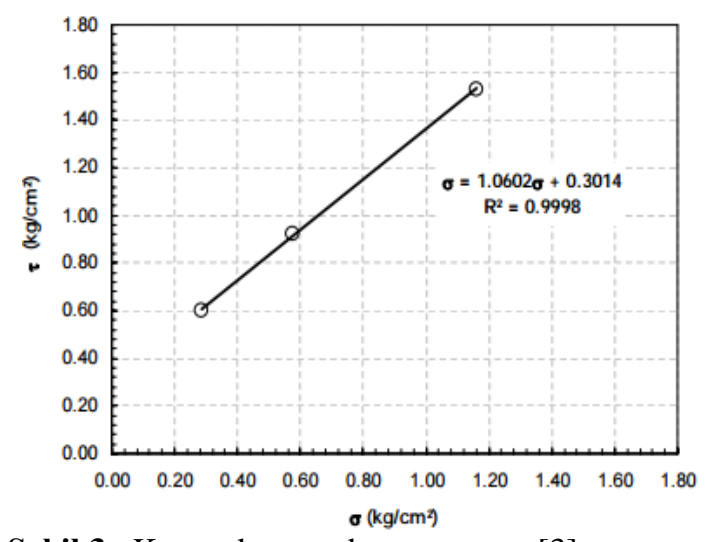

Şekil 3. Kesme kutusu deney sonucu [3]

Stabilize malzeme üzerinde yapılan Piknometre deneyi ile zemin dane birim hacim ağırlığ $2,64 \mathrm{gr} / \mathrm{cm}^{3}$ olarak bulunmuştur. Birleştirilmiş zemin sınıflamasına göre stabilize malzeme iyi derecelenmiş çakıl-siltli çakıl (GW-GM) olarak sınıflandırılmıştır (Şekil 4).

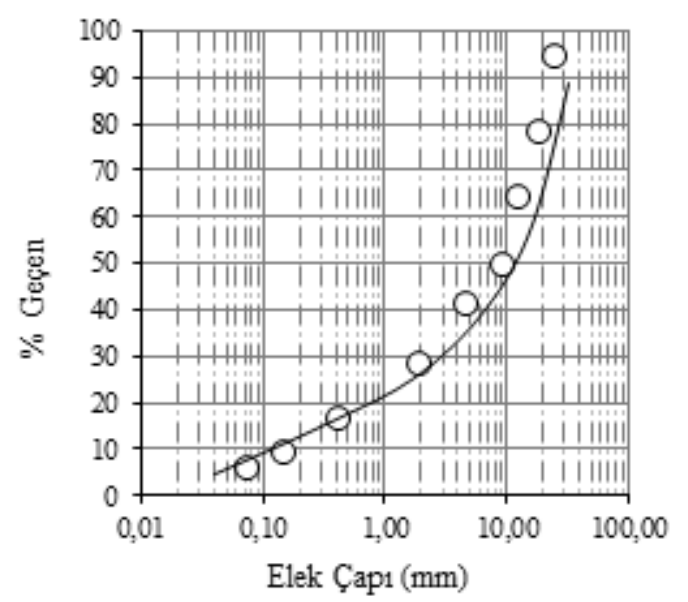

Şekil 4. Elek analizi sonucu [3]

\subsection{Deney Düzeneği}

Yapılan deneysel çalışmalar Ç.Ü. İnşaat Mühendisliği Laboratuvarında özel olarak hazırlanmış $38 \mathrm{~cm}$ çapında ve $42 \mathrm{~cm}$ derinliğinde dairesel rijit bir kasa ve motorlu yükleme düzeneği kullanılarak yapılmıştır (Şekil 5). Homojen kil zemin durumunun incelendiği deney setlerinde numune hazırlama aşamasında, 
araziden getirilen blok numuneler küçük parçalara ayrılıp, $105 \pm 5^{\circ} \mathrm{C}$ sabit sıcaklıktaki etüvde 24 saat süreyle kurutulmuştur.

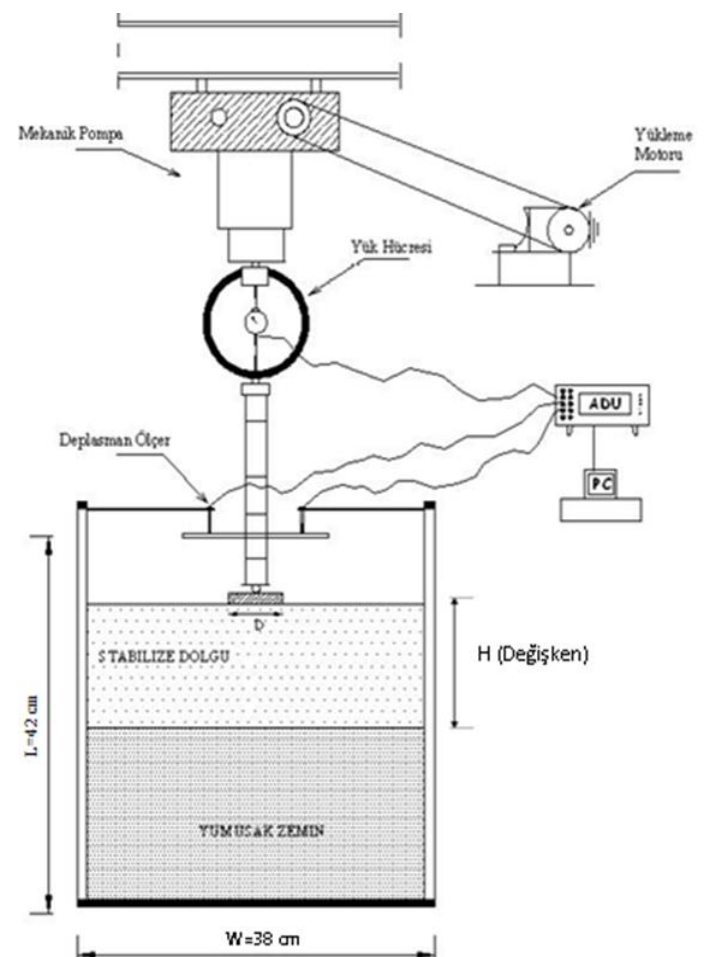

Şekil 5. Laboratuvar model deney düzeneği [3]

Öğütülen kuru zemin numuneleri arazideki ortalama su içeriği olan \%23'te hazırlanıp, homojen bir su dağılımı oluşuncaya kadar yoğrulmuştur. Hazırlanan numuneler, eşit ağırlıklarda $(5 \mathrm{~kg})$ poşetlendikten sonra, nem kaybını önlemek için kür odasında 24 saat süreyle bekletilmiştir. Kil numuneler, kasa içerisine, sabit kalınlıkta tabakalar halinde yerleştirilmiştir. Zemin kalıba boșaltıldıktan sonra, özel olarak hazırlanmıș tokmak ile, sabit standart bir enerji altında sıkıştırılmıştır [5]. Kullanılan tokmak $2 \mathrm{~kg}$ ağırlıkta olup, düşme yüksekliği $20 \mathrm{~cm}$ tutulmuştur. Sabit kalınlıktaki tabaka için ortalama olarak 80 düşüş ile sıkıştırma işlemi tamamlanmıştır. Sıkıştırma esnasında; her sabit kalınlık için, gerekli zemin numunesinden su muhtevası örnekleri alınmış ve sıkıştırılan her 5 $\mathrm{cm}$ tabaka için, el penetrometresi ile mukavemet kontrolü yapılmıştır. Sıkıştırma işlemi tamamlandiktan sonra temeller, üst tabakanın ortasına yerleştirilerek su terazisi ile dengesi kontrol edilmiştir. Yükleme elemanları monte edildikten sonra yük, 2,5 kN kapasiteli yük halkasından temele aktarılmıştır. Yükün temele dik olarak etkimesi için temelle yükleme elemanı arasına çelik bilye konulmuştur [6]. Yükleme elemanları monte edildikten sonra, üç adet deplasman ölçer kasa üzerine sabitlenmiştir. Deneyde yük-deplasman okumaları, ADU (Veri Kaydetme Ünitesi) ile kaydedilmiş ve DIALOG yazılımı ile, bu okumalar sayısal değerlere dönüştürülmüştür. Yüklemeye, önemli bir oturma (temel çapının en az \%20'si) meydana gelinceye kadar devam edilmiştir.

Granüler dolgu katkısının dikkate alındığı tabakalı zemin durumları için gerçekleştirilen deneylerde ise, kil tabakasının yukarıdaki prosedüre göre yerleşiminin ardından uygun zemin kotuna ulaşıldığında, temel çapına bağlı olarak, yerleştirilecek stabilize malzeme miktarları ayarlanmıştır. Optimum su içeriği olan \%7'de hazırlanan malzeme, homojen bir su dağılımı oluşuncaya kadar yoğrulmuştur. Sabit bir kalınlık için gereken stabilize malzeme kasa içerisine boşaltılmış ve dinamik bir sıkıştırıcı ile istenilen kalınlığı kadar, üniform bir enerji uygulanarak, üst tabaka stabilize dolgu tabakalar halinde oluşturulmuştur. Yükleme ve bağlantı elemanlarının da sisteme dahil edilmesi ile deney düzeneği hazırlanmış olmaktadır (Şekil 6).

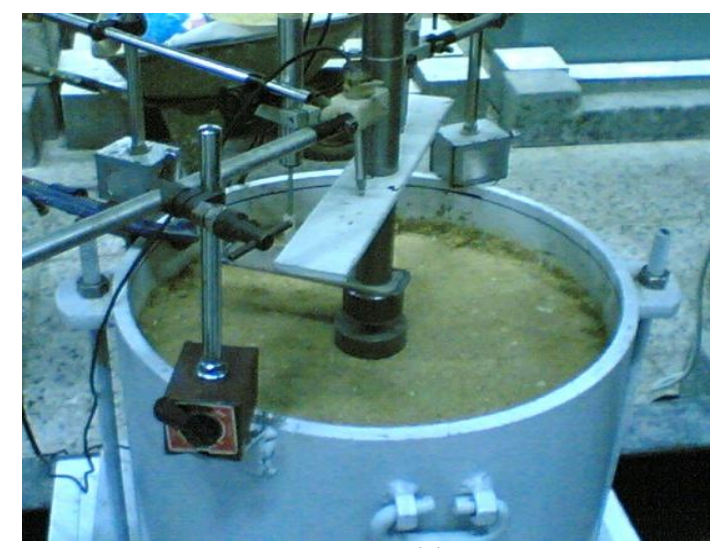

Şekil 6. Sistemin yüklemeye hazır hale getirilmesi [7] 


\subsection{Deney Programı}

Laboratuvar model deneylerinde; homojen kil zemin durumları ve stabilize dolgu kalınlıkları, temel çapına (D) bağlı olarak, $\mathrm{H}=0,25 \mathrm{D}$ ile $\mathrm{H}=1,50 \mathrm{D}$ arasında değişen tabakalı zemin durumları için deneyler, 6 ve $9 \mathrm{~cm}$ çaplı rijit, dairesel temellerin yüklenmesi ile yapılmıştır. Elde edilen iyileşmelere referans olması açısından, sadece kil zemin durumundaki, bu deneyler yapılmıştır. Stabilize dolgu katkısı ile yapılan deneylerde, farklı stabilize kalınlıklarının (H), sistemin taşıma kapasitesine olan etkisi toplam 10 deney ile araştırılmıştır (Çizelge 2).

Çizelge 2. Stabilize dolgu katkısıyla yapılan deneyler

\begin{tabular}{|c|c|c|}
\hline Temel Çapı (D) & $\mathbf{9 c m}$ & $\mathbf{6 c m}$ \\
\hline \multirow{2}{*}{$\begin{array}{c}\text { Granüler Stabilize } \\
\text { Dolgu Kalınlı̆̆ı } \\
(\mathbf{H})\end{array}$} & $0,25 \mathrm{D}$ & $0,25 \mathrm{D}$ \\
\cline { 2 - 3 } & $0,50 \mathrm{D}$ & $0,50 \mathrm{D}$ \\
\cline { 2 - 3 } & $1,00 \mathrm{D}$ & $1,00 \mathrm{D}$ \\
\cline { 2 - 3 } & $1,50 \mathrm{D}$ & $1,50 \mathrm{D}$ \\
\hline Deney Sayısı & 4 & 4 \\
\hline
\end{tabular}

Deneylerden elde edilen yük-oturma eğrileri üzerinden, taban basıncı (q) ve temel çapına bölünerek boyutsuz hale getirilen oturma oranı (s/D) arasındaki ilişkiden göçme yükleri belirlenmiştir (Şekil 7).

Homojen zemin durumu ve farklı stabilize kalınlıkları için gerçekleştirilen model deney sonuçları iki farklı temel çapı için Şekil 7'deki gibi karşılaştırıldığında, temel çapları arasında herhangi bir ölçek etkisinin bulunmadığı görülmüştür. Göçme yükü değeri olarak her bir deney için, grafiklerde eğriliğin değiştiği noktaların yeri, teğetlerin kesiştirilmesi yöntemi ile elde edilmiştir.

\section{MODEL DENEY SONUÇLARININ ANALITIK YÖNTEMLE KARŞILAŞTIRILMASI}

$\mathrm{Bu}$ bölümde, yapılan stabilize katkılı deneysel çalışmaların, doğruluğunu karşılaştırmak için teorik yöntemlerle karşılaştırmalar yapılmıştır.
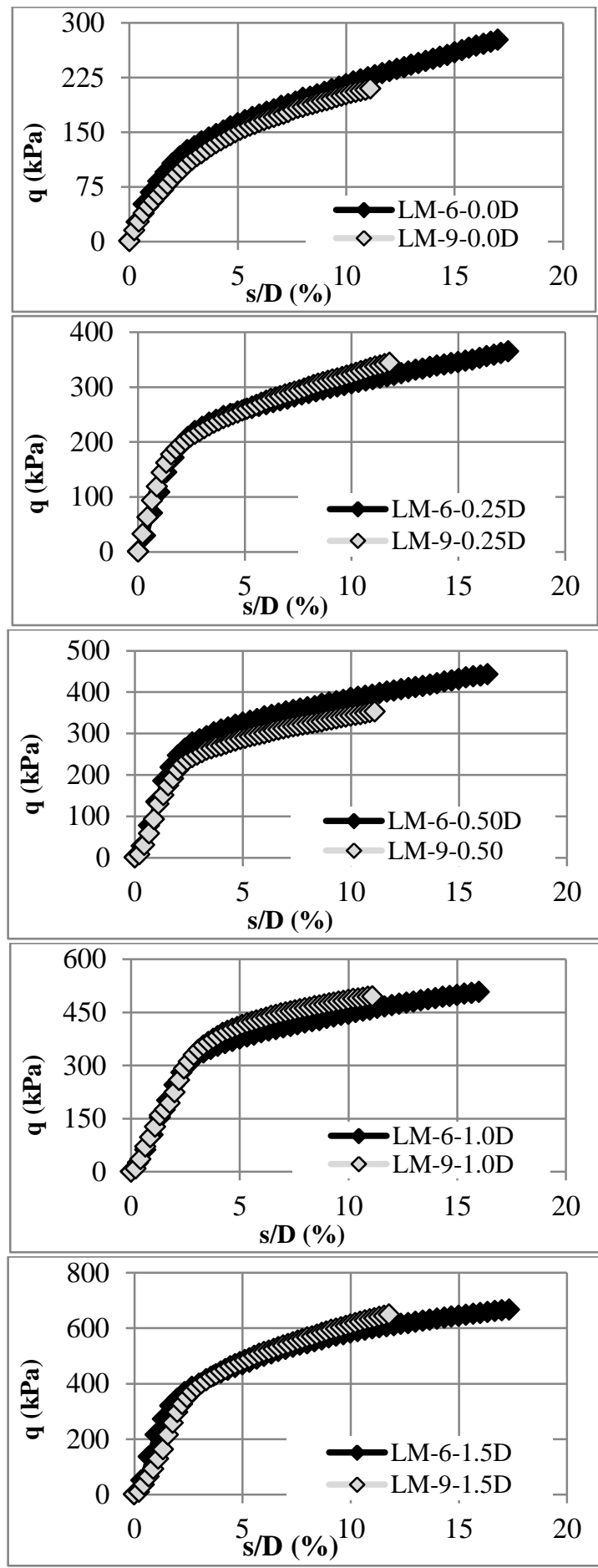

Şekil 7. Farklı stabilize dolgu kalınlıklarına göre ölçek etkisinin incelenmesi 
Burada tabakalı zeminlere ait taşıma gücü yöntemlerinden Önalp [8] tarafindan önerilmiş olan bir yaklaşım kullanılmıştır. $\mathrm{Bu}$ yaklaşıma göre; sorunlu bir kil tabakası üstüne oturan kumun taşıma gücü aşağıdaki formüller ile hesaplanmaktadır (Eşitlik 1).

$$
\begin{aligned}
q_{u} & =\left[1+2 \frac{H}{B} \tan \alpha_{c}\right]\left(S_{u} N_{c}+\rho^{\prime} D_{f}+\rho^{\prime} H\right) \\
& +\left[\frac{K_{p} \sin \left(\phi^{\prime}-\alpha_{c}\right)}{\cos \phi^{\prime} * \cos \alpha_{c}}\right] *\left(\frac{H}{B}\right)\left(\rho^{\prime} D_{f}+\rho^{\prime} H\right) \\
& -\rho^{\prime} H\left[1+2 \frac{H}{B} \tan \alpha_{c}\right]
\end{aligned}
$$

Taşıma gücünün bulunabilmesi için Eşitlik 1'de geçen ifadeler, Eşitlik 2-6 arasında verilmiştir.

$$
\begin{aligned}
& \alpha_{\mathrm{c}}=\tan ^{-1}\left[\frac{\left(\sigma_{\mathrm{mc}} / \mathrm{S}_{\mathrm{u}}\right)-\left(\sigma_{\mathrm{ms}} / \mathrm{S}_{\mathrm{u}}\right) *\left(1+\sin ^{2} \phi^{\prime}\right)}{\cos \phi^{\prime} * \sin \phi^{\prime} *\left(\sigma_{\mathrm{ms}} / \mathrm{S}_{\mathrm{u}}\right)+1}\right] \\
& \sigma_{\mathrm{mc}} / \mathrm{S}_{\mathrm{u}}=\mathrm{N}_{\mathrm{c}} \mathrm{S}_{\mathrm{u}}\left(1+\frac{1}{\lambda_{\mathrm{c}}} \frac{\mathrm{H}}{\mathrm{B}} \frac{\lambda_{\mathrm{p}}}{\lambda_{\mathrm{c}}}\right) \\
& \sigma_{\mathrm{ms}} / \mathrm{S}_{\mathrm{u}}=\frac{\sigma_{\mathrm{mc}} / \mathrm{S}_{\mathrm{u}}-\sqrt{\left(\sigma_{\mathrm{mc}} / \mathrm{S}_{\mathrm{u}}\right)^{2}-\cos ^{2} \phi^{\prime}\left(\left(\sigma_{\mathrm{mc}} / \mathrm{S}_{\mathrm{u}}\right)^{2}+1\right)}}{\cos ^{2} \phi^{\prime}} \\
& \lambda_{\mathrm{p}}=\frac{\rho^{\prime} \mathrm{D}_{\mathrm{f}}}{\rho^{\prime} \mathrm{B}} \\
& \lambda_{\mathrm{c}}=\frac{\mathrm{S}_{\mathrm{u}} \mathrm{N}_{\mathrm{c}}}{\rho^{\prime} \mathrm{B}}
\end{aligned}
$$

$\mathrm{Bu}$ hesaplarda kullanılacak kil zemin, granüler dolgu ve dairesel temele ait parametreler Çizelge 3'te verilmiştir.

Çizelge 3. Hesaplamalarda kullanılacak parametreler

\begin{tabular}{|c|c|}
\hline Temel Derinliği $\left(\mathrm{D}_{\mathrm{f}}\right)$ & 0 \\
\hline Temel Çapı $(\mathrm{B}), \mathrm{m}$ & $0,09 / 0,06$ \\
\hline İçsel Sürtünme Açısı $(\phi){ }^{\circ}$ & 43 \\
\hline Kohezyon $\left(\mathrm{c}_{\mathrm{u}}\right), \mathrm{kN} / \mathrm{m}^{2}$ & 40 \\
\hline Birim Hacim A ğırlığ $(\rho), \mathrm{kN} / \mathrm{m}^{3}$ & 16 \\
\hline Su Altında BHA $\left(\rho^{\prime}\right), \mathrm{kN} / \mathrm{m}^{3}$ & 6,19 \\
\hline Taşıma Gücü Parametresi $\left(\mathrm{N}_{\mathrm{c}}\right)$ & 5,14 \\
\hline $\begin{array}{c}\text { Temel Altından Stabilize Kalınlığ } 1 \\
(\mathrm{H}) \mathrm{m}\end{array}$ & $\mathrm{B} *(\mathrm{H} / \mathrm{B})$ \\
\hline
\end{tabular}

Buna göre, tabakalı zemin durumları için gerçekleştirilen 8 adet deney sonucu ve analitik çözüm yöntemi esas alınarak hesaplanan göçme yükü değerleri Çizelge 4'te verilmiştir. Farklı stabilize dolgu kalınlıkları ve göçme yükleri arasındaki ilişki, temel çaplarına göre ayrı ayrı sırasıyla Şekil 8'de verilmiştir.

Çizelge 4. Deneylere ait göçme yükü değerleri

\begin{tabular}{|c|c|c|c|}
\hline $\begin{array}{c}\text { Temel } \\
\text { Çap1 } \\
\text { D (cm) }\end{array}$ & $\begin{array}{c}\text { Dolgu } \\
\text { Kalınlığ1 }\end{array}$ & $\begin{array}{c}\text { Deney } \\
\text { Göçme } \\
\text { Yükü } \\
(\mathrm{kPa})\end{array}$ & $\begin{array}{c}\text { Analitik } \\
\text { Göçme } \\
\text { Yükü } \\
(\mathrm{kPa})\end{array}$ \\
\hline \multirow{4}{*}{6} & $0,25 \mathrm{D}$ & 230,0 & 247,7 \\
\cline { 2 - 4 } & 0,50D & 284,0 & 290,3 \\
\cline { 2 - 4 } & $1,00 \mathrm{D}$ & 362,0 & 376,9 \\
\cline { 2 - 4 } & $1,50 \mathrm{D}$ & 404,0 & 465,4 \\
\hline \multirow{4}{*}{9} & $0,25 \mathrm{D}$ & 198,0 & 247,8 \\
\cline { 2 - 4 } & $0,50 \mathrm{D}$ & 270,0 & 290,8 \\
\cline { 2 - 4 } & $1,00 \mathrm{D}$ & 387,0 & 378,8 \\
\cline { 2 - 4 } & $1,50 \mathrm{D}$ & 420,0 & 469,58 \\
\hline
\end{tabular}

Bu çalışma kapsamında yer alan iki farklı dairesel temel için, deney ve analitik yaklaşımlardan elde edilen taşıma gücü değerleri ayrı ayrı değerlendirildiğinde, hata oranları ortalama olarak, $6 \mathrm{~cm}$ çaplı temel için \%10,2 iken $9 \mathrm{~cm}$ ' lik temel için bu değer \%8,8 mertebelerindedir. Böylece; her iki model deney için hata oranı değeri ortalama \%9,5 olarak elde edilmiştir. Bu durumda; analitik sonuçların deneysel çalışmalarla genel bir uyum içerisinde olduğu görülmüştür.

\section{SONUÇLAR}

$\mathrm{Bu}$ çalışmada, yumuşak kil zeminler üzerine inşa edilen dairesel temeller altına yerleştirilen farklı kalınlıklardaki stabilize dolgu tabakası katkısının, iki farklı çaptaki temel için taşıma kapasitesinde meydana getirdiği değişimler, hem küçük ölçekli laboratuvar deneyleri, hem de analitik çözüm yöntemi ile irdelenmiştir.

- Karşılaştırılan iki farklı temel çapı arasında, kayda değer bir ölçek etkisinin oluşmadığ edilmiştir. 

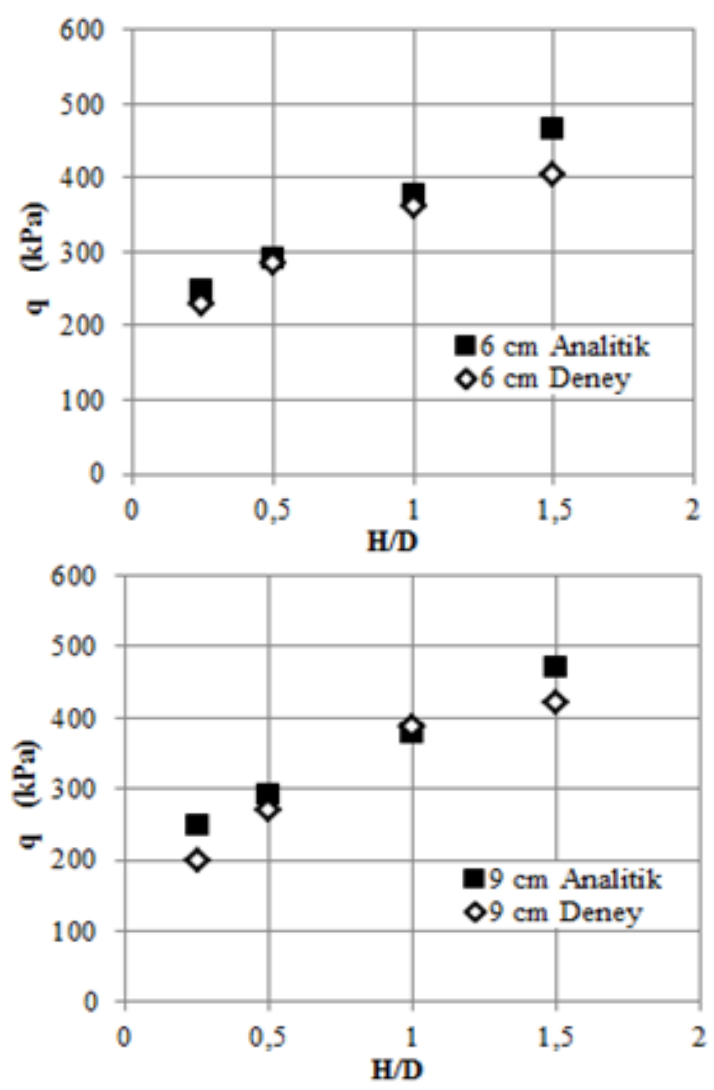

Şekil 8. 6 ve $9 \mathrm{~cm}$ çaplı temellerde deney ve analitik sonuçların karşılaştırılması

- Deneysel çalışmalar, yine tabakalı zeminlerin taşıma kapasitelerinin hesaplanabilmesi için literatürde yer alan analitik çözüm yöntemi ile kıyaslanmıştır. Elde edilen taşıma gücü değerlerinden, hem deney hem de analitik sonuçların birbirleri ile uyumlu olduğu görülmüştür.

- İki farklı temel çapı ve 8 farklı tabakalı zemin profilinde deneyler gerçekleştirilmiştir. Elde edilen sonuçlar, analitik yaklaşımdan elde edilen göçme yükleri ile kıyaslandığında, aralarında ortalama \%9,5'luk bir hata oranı elde edilmiştir.

\section{TEŞEKKÜR}

$\mathrm{Bu}$ makalede sunulan çalışma, 106M496 numaralı proje kapsamında TÜBİTAK (Türkiye Bilimsel ve
Teknolojik Araştırma Kurumu) tarafından desteklenmiştir.

\section{KAYNAKLAR}

1. Hamed, J. T., Das, B. M. ve Echelberger, W. F., 1986. Bearing Capacity of a Strip Foundation on a Granular Trench in Soft Clay. Civil Engineering for Practicing and Design Engineers, Pergamon Press, 5 (5), 359.

2. Madhav, M. R. ve Vitkar, P. P., 1978. Strip Footing on Weak Clay Stabilizated with a Granular Trench or Pile. Canadian Geotechnical Journal 15(4), 605.

3. Misir, G. 2008. Granüler Dolgu ile İyileştirilen Yumuşak Kil Zeminlere Oturan Temellerin Analizi. Yüksek Lisans Tezi, Çukurova Üniversitesi Fen Bilimleri Enstitüsü, Adana.

4. Laman, M., Yıldız, A., Örnek, M. ve Demir, A., 2009. Yumuşak Kil Zeminlerin Geogrid Donatı ile Güçlendirilmesi, TÜBİTAK Araştırma Projesi (No: 106M496), Ankara, 528 sayfa.

5. Dash, S. K. Sireesh, S., Sitharam, T. G. 2003. Model Studies on Circular Footing Supported on Geocell Reinforced Sand Underlain by Soft Clay. Geotextiles and Geomembranes, 21, 197-219.

6. El Sawwaf, M. A., 2007. Behavior of Strip Footing on Geogrid-Reinforced Sand Over a Soft Clay Slope. Geotextiles and Geomembranes, 25, 50-60.

7. Demir, A. Örnek, M. Laman, M. Yildiz, A., Misir, G. 2009. Model Studies of Circular Foundations on Soft Soils. Geotechnics of Soft Soils-Focus on Ground ImprovementKarstunen \& Leoni (eds), Taylor, Francis Group, London, ISBN 978-0-415-47591-4.

8. Önalp, A., Sert, S. 2000. Geoteknik Bilgisi III Bina Temelleri. Birsen Yayınları. İstanbul. 
